\title{
Perfil de resistência de microrganismos isolados em fones de ouvidos de alunos de uma instituição de ensino superior de Juazeiro do Norte-CE
}

\section{Resistance profile of isolated microorganisms in headphones of students of a higher education institution in Juazeiro do Norte-CE}

Felipe Raimundo Bezerra Barros, Maria de Fátima Guedes Monteiro,

Dárcio Luiz de Sousa Júnior, Pedro Everson Alexandre de Aquino,

Cícero Roberto Nascimento Saraiva, Maria Karollyna do Nascimento Silva Leandro, Rakel Olinda Macedo da Silva e Lívia Maria Garcia Leandro.

\section{RESUMO:}

Como citar este artigo: BARROS, FELIPE R. B.; MONTEIRO, MARIA F. G.; JÚNIOR, DÁRCIO L. S.; AQUINO, PEDRO E. A.; SARAIVA, CICERO R. N.; LEANDRO, MARIA K. N. S.; SILVA, RAKEL O. M.; LEANDRO, LIVIA M. G. Perfil de resistência de microrganismos isolados em fones de ouvidos de alunos de uma instituição de ensino superior de Juazeiro do Norte-CE. Revista Saúde (Sta. Maria). 202I; n. I, v. 47.

\footnotetext{
Autor correspondente:

Nome: Felipe Raimundo Bezerra Barros

E-mail: felipe98barros@gmail.com Telefone: (87) 99604-2 193 Formação Profissional: Formado em Biomedicina pelo Centro Universitário Dr. Leão Sampaio (UNILEÃO), Juazeiro do Norte, Ceará, Brasil. Pós-graduando em Hematologia (UNILEÃO).
}

\section{Filiação Institucional:}

Centro Universitário Dr. Leão Sampaio (UNILEÃO), Juazeiro do Norte, Ceará, Brasil.

Endereço para correspondência: Coronel Pedro Cícero, 162

Bairro: Centro

Cidade: Trindade

Estado: Pernambuco

CEP: 52250-000

\section{Data de Submissão:}

12/05/2020

\section{Data de aceite:}

25/01/2021

Conflito de Interesse: Não há conflito de interesse
Objetivo: Avaliar o perfil de resistência de microrganismos isolados em fones de ouvidos de alunos de uma instituição de ensino superior (IES) de Juazeiro do Norte-CE. Métodos: Foram adquiridas 40 amostras aleatoriamente com os discentes da IES e acondicionadas em tubos contendo solução salina, essas amostras foram levadas para o laboratório de microbiologia do Centro Universitário Dr. Leão Sampaio, onde foram abertos e inoculados em meio Brain Hair Infusion (BHI), onde foram incubados em estufa bacteriológica a $37^{\circ} \mathrm{C}$. Após 24 horas foi realizado o semeio nos meios de cultura (Ágar Manitol Salgado, Ágar Sangue e Ágar Eosina Azul de Metileno - EMB), posteriormente foram realizadas as provas bioquímicas para confirmação das espécies, por fim realizou-se 0 antibiograma utilizando os discos de Amicacina, Gentamicina, Ofloxacina, Oxacilina, Norfloxacina, Ciprofloxacina e Penicilina G. Resultados: Foi observado que $100 \%$ das amostras encontravam-se contaminadas por um ou mais tipos de microrganismos (12,5\% de Streptococcus sp, $70 \%$ de Staphylococcus aureus, Staphylococcus coagulase negativa 30\%, Citrobacter freundii 7,5\%, Enterobacter aerogenes $2,5 \%$ e Cândida sp. $35 \%$ ). A partir do antibiograma foi possível observar resistência das cepas para os antibióticos Penicilina G e Oxacilina. Considerações Finais: Baseado nos resultados obtidos é necessário que os discentes tenham um cuidado maior com os fones de ouvidos uma vez que, eles mal higienizados podem aglomerar diversos tipos de bactérias resistentes e podem causar infecções no canal auditivo.

PALAVRAS-CHAVE: Antibiograma; Fones de ouvido; Microrganismos.

\section{ABSTRACT}

Objective: To evaluate the resistance profile of isolated microorganisms in headphones of students of a higher education institution (IES) of Juazeiro do Norte-CE. Methods: 40 samples were randomly acquired with the students of IES and packed in tubes containing saline solution, these samples were taken to the microbiology laboratory of Dr. Leão Sampaio University Center, where they were opened and inoculated in Brain Hair Infusion (BHI) medium, where they were incubated in a bacteriological greenhouse at $37^{\circ} \mathrm{C}$. After 24 hours the sowing was performed in the culture media (Salt Mannitol Ágar, Blood Ágar and Methylene Blue Eosin Ágar - EMB), then the biochemical tests were performed to confirm the species, finally the antibiogram was performed using the discs of Amikacin, Gentamicin, Ofloxacin, Oxacillin, Norfloxacin, Ciprofloxacin and Penicillin G. Results: It was observed that $100 \%$ of the samples were contaminated by one or more types of microorganisms (12.5\% Streptococcus sp, $70 \%$ Staphylococcus aureus, Staphylococcus coagulase negative 30\%, Citrobacter freundii $7.5 \%$, Enterobacter aerogenes $2.5 \%$ and Candida sp. $35 \%$ ). From the antibiogram it was possible to observe resistance of the strains to the antibiotics Penicillin $G$ and Oxacillin. Final Considerations: Based on the results obtained it is necessary that the students have a greater care with the earphones since, they badly sanitized can agglomerate several types of resistant bacteria and can cause infections in the auditory canal. 


\section{INTRODUÇÃO}

O uso indiscriminado de antibióticos facilita na disseminação de bactérias resistentes, fazendo com que proporcionem uma maior complicação nas infecções, uma vez que podem transferir o seu material genético para outras bactérias, desenvolvendo assim mecanismos de defesa contra os antibióticos'. Segundo Macedo e Falcão $(2011)^{2}$ a resistência bacteriana acontece quando uma bactéria é capaz de desenvolver-se in vitro na presença da concentração inibitória que a droga atinge no sangue.

As infecções do canal auditivo podem estar correlacionadas com problemas de limpeza auricular acompanhado do uso de fones, acarretando uma alteração da microbiota normal do ouvido, provocando otite, infecções de diversos graus, inflamação acompanhada de dor, febre e aparecimento de fluido na caixa timpânica ${ }^{3,4}$.

As mãos são condutoras de muitos microrganismos, sejam eles da nossa microbiota normal ou microrganismo transitórios, que provocam uma propagação de agentes infecciosos, os fones de ouvidos podem atuar como fômites pois são objetos inanimados e estão em contato frequente com vários ambientes e pessoas5, contribuindo assim para a transmissão de doenças infectocontagiosas, que variam de leve a grave levando em conta o agente etiológico que transmiti a patologia $a^{6,7}$.

Staphylococcus sp. e Streptococcus sp. são bactérias Gram positivas, oportunistas que atingem indivíduos de imunidade baixa, podendo causar infecções no canal auditivo ou até mesmo sepse, sendo que a maioria apresenta resistência a antimicrobianos. As bactérias Gram negativas possuem representantes comensais e alguns tipos são patogênicos, destacando-se como as causadoras mais comuns de infecções urinárias, além de provocarem diarréia8,9.

Fones de ouvidos são objetos consideravelmente utilizados pela população, e por estarem expostos a ambientes passíveis de contaminação, podem contribuir para disseminação de doenças infectocontagiosas principalmente ao seu usuário, que na maioria das vezes não faz assepsia do objeto, levando os microrganismos ao contato direto com o canal auditivo. Assim, o objetivo deste trabalho foi avaliar a presença de microrganismos em fones de ouvidos correlacionando com o seu perfil de resistência.

\section{MÉTODO}

\section{Obtenção das amostras}

Foram colhidas 40 amostras de fones de ouvidos de diferentes tipos (intra e supra aurais), sendo adquiridas aleatoriamente com alunos de uma IES da cidade de Juazeiro do Norte, Ceará. As amostras foram analisadas no laboratório de microbiologia do Centro Universitário Dr. Leão Sampaio. Todas as análises foram realizadas em triplicata. 


\section{Reagentes e Meios de cultura}

Os reagentes utilizados para análise foram Peróxido de hidrogênio, reagente de Indol e Cloreto férrico à 10\%. Os meios de cultura utilizados no estudo: Brain Heart Infusion (BHI), Ágar Eosina Azul de Metileno (EMB), Ágar Tríplice Açúcar Ferro (TSI), Ágar Citrato de Simmons, Ágar Sulfato/Indol/Motilidade (SIM), Ágar Fenilalanina, Ágar Uréia de Christensen, Ágar Sangue e Ágar Manitol Salgado.

\section{Preparação dos meios de cultura}

Todos os meios utilizados foram preparados de acordo com as especificações do fabricante e esterilizados em autoclave. Os meios Ágar Sangue, Ágar Eosina Azul de Metileno (EMB) e Ágar Manitol Salgado foram distribuídos em placas de petri estéreis e os meios Brain Heart Infusion (BHI), Ágar Tríplice Açúcar Ferro (TSI), Ágar Citrato de Simmons, meio SIM, Ágar Fenilalanina e Ágar Uréia de Christensen foram distribuídos de forma asséptica em tubos estéreis.

\section{Coleta das amostras e Identificação das espécies bacterianas}

A coleta foi realizada com um swab umedecido com solução salina e inoculado em meio de enriquecimento BHI que foi incubado por 24 horas a $37^{\circ} \mathrm{C}$ em estufa bacteriológica. A partir do $\mathrm{BHI}$ com crescimento bacteriano foi feito o semeio em Ágar Manitol através da técnica de esgotamento, e posteriormente foi incubado em estufa a $37{ }^{\circ} \mathrm{C}$ pelo período de 24 horas. Staphylococcus aureus, bactéria fermentadora de manitol, produz colônias grandes e rodeadas de uma zona amarelada ${ }^{10}$. Após a observação do crescimento em Ágar manitol foram realizadas provas bioquímicas, catalase e coagulase, para confirmação da espécie.

Para realizar o teste da catalase foi depositada uma gota de peróxido de hidrogênio $(\mathrm{H} 2 \mathrm{O} 2)$ em uma lâmina estéril e em seguida foi retirada, com o auxílio de uma alça de platina estéril, uma colônia do meio de cultura, sendo essa colocada sobre a gota para observação da formação de bolhas ${ }^{10}$. As colônias com positividade nos testes da catalase foram submetidas ao teste de coagulase, a fim de identificar a espécie de Staphylococcus, já que somente Staphylococcus aureus (S. aureus) possui esta enzima11.

Para realização do teste da coagulase em tubo foi retirado, com o auxílio de uma alça de platina estéril, uma colônia suspensa e colocada juntamente com $0,5 \mathrm{~mL}$ de plasma com EDTA em um tubo estéril e incubado por 24 horas à $37^{\circ} \mathrm{C}$ em estufa para posterior observação do coágulo ${ }^{10}$.

A partir do semeio no meio Ágar Sangue sua posterior incubação em estufa a $37^{\circ} \mathrm{C}$ por 24 horas, e o teste de catalase sendo negativo, foi observado o grau de intensidade da hemólise, tendo em vista que serão identificadas no presente estudo apenas bactérias com hemólise total (beta). Após a observação da hemólise foi feito o teste de PYR no qual determina a atividade da enzima pirrolidonil arilamidase produzida pelo Streptococcus pyogenes, mas não pelos demais estreptococos $\beta$-hemolíticos e confirmado com o $\mathrm{NaCl} 6,5 \%{ }^{10}$. 
A partir do $\mathrm{BH}$ com crescimento bacteriano foi realizado o semeio de todas as amostras, através da técnica de esgotamento, no meio Ágar Eosina Azul de Metileno (EMB), os quais foram incubados em estufa a $37^{\circ} \mathrm{C}$ por 24 horas. Após isso foi observado o crescimento das colônias. As colônias onde houve crescimento foram submetidas aos seguintes testes bioquímicos: Ágar Triple Sugar Iron (TSI), que é utilizado para diferenciar os bastonetes gram-negativos, utilizando a fermentação de carboidratos e produção de sulfeto de hidrogênio; Ágar Citrato de Simmons, indicado para determinar a capacidade de certas bactérias de utilizarem o citrato como única fonte de carbono para o seu metabolismo; Ágar Indol Sulfide Motility (SIM), meio recomendado para diferenciação de enterobactérias com base na motilidade dos micro-organismos e produção de sulfito de hidrogênio e indol; Ágar Fenilalanina, recomendado para a diferenciação de membros dos grupos Proteus e Providencia de outras enterobactérias e Ágar Uréia de Christensen, usado para auxiliar a diferenciação de Gram-negativas entéricas, com base na hidrólise de ureia ${ }^{10}$.

Realizou-se uma suspensão bacteriana na escala 0,5 de MacFarland (1,5 x $108 \mathrm{bac} / \mathrm{mL})$ para todas bactérias identificadas. A partir dessa suspensão, utilizando um swab estéril, foi realizado o semeio em tapete em Ágar MullerHinton e no Ágar Sangue no caso dos Streptococcus sp., que são meios específicos para realização de antibiograma segundo método de difusão em disco. Após o semeio foi adicionado os discos de amicacina, gentamicina, ofloxacina, oxacilina, norfloxacina, ciprofloxacina e penicilina $\mathrm{G}^{11}$.

As placas de antibiograma foram incubadas em estufa à $37^{\circ} \mathrm{C}$ por 24 horas, por fim, efetuou-se a análise do perfil de resistência através da medição em milímetros dos halos de inibição gerados, sendo estes comparados com a tabela padronizada pelo Clinical and Laboratory Standards Institute ${ }^{12}$.

\section{Análise dos dados}

Os dados obtidos foram organizados e expostos em porcentagem utilizando o programa Microsoft Excel 2016.

\section{RESULTADOS}

Após a realização da análise microbiológica de 40 fones de ouvidos dos alunos de uma instituição de ensino superior, foi observado que $100 \%$ das amostras se encontravam contaminadas por um ou mais tipos de microrganismos pesquisados. A porcentagem de crescimento dos microrganismos (Staphylococcus aureus, Staphylococcus coagulase negativa, Streptococus sp., Citrobacter freundii, Enterobacter aerogenes) encontrados em fones de ouvidos de alunos de uma instituição de ensino superior de Juazeiro do Norte-CE, estão expostas no Gráfico 1.

No Ágar Sangue também foi observado crescimento de estruturas fúngicas. Após descartar uma possível contaminação, foi realizada uma análise microscópica com a ajuda de colocação de Gram, onde foi constatado a presença de hifas septadas, sugestivo de Cândida sp. 
Gráfico 1: Porcentagem de microorganismos encontrados nas amostras de fones de ouvido de uma instituição de ensino superior de Juazeiro do Norte-CE.

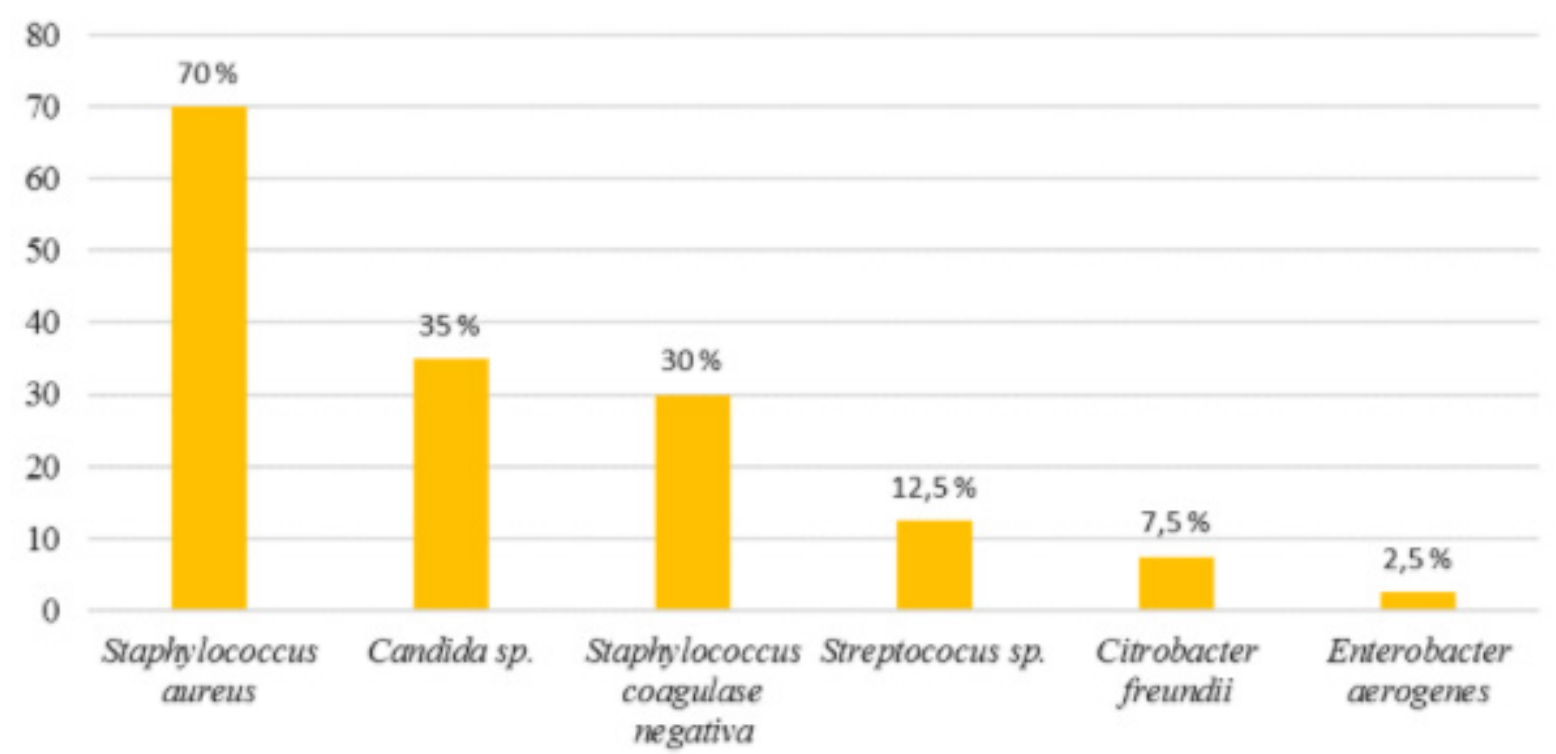

A resistência bacteriana de Staphylococcus aureus obtida nesse estudo está representada no Gráfico 2. Demostrou-se uma maior sensibilidade das cepas em cinco dos setes antibióticos testados.

Gráfico 2: Perfil de resistência de Staphylococcus aureus.

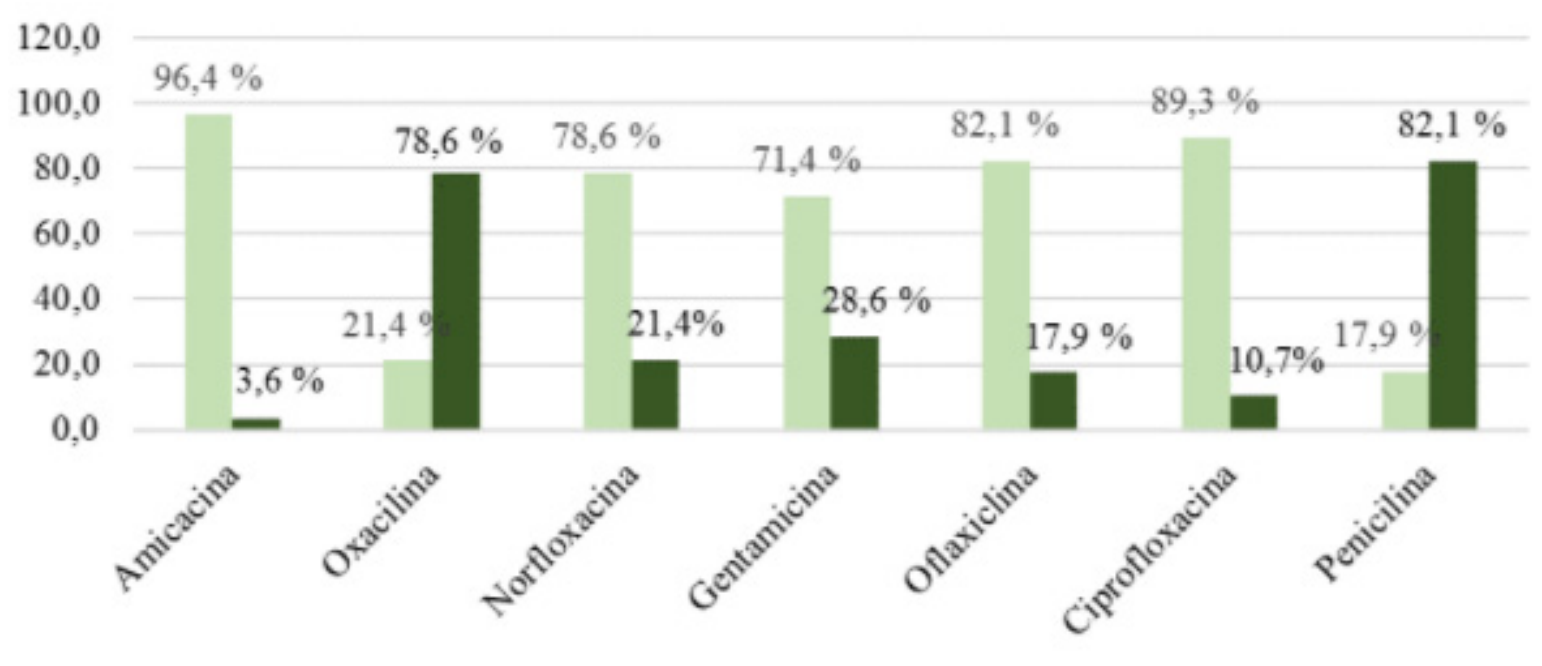

Sensivel $=$ Resistente

Diante das análises realizadas a partir do perfil de resistência de $S$. aureus foi possível identificar que ocorreu uma maior resistência das cepas à Penicilina (82,1\%) e Oxacilina (78,6\%). Os antibióticos que apresentaram um maior percentual de sensibilidade foram Amicacina $(96,4 \%)$, Ciprofloxacina $(89,3 \%)$, Oflaxiclina $(82,1 \%)$, Norfloxacina $(78,6 \%)$ e Gentamicina $(71,4 \%)$.

No Gráfico 3, podemos observar resistência de 100\% frente aos antibióticos Oxacilina e Penicilina, já nos discos de Amicacina, Norfloxacina, Oflaxicina e Ciprofloxacina é notável a sensibilidade de 100\% das bactérias, entretanto frente ao antibiótico de Gentamicina, 75\% dos microrganismos foram sensíveis e 25\% foram resistente. 
Gráfico 3: Perfil de resistência das bactérias Gram-negativas encontradas nas amostras de fones de ouvido de uma instituição de ensino superior de Juazeiro do Norte-CE.

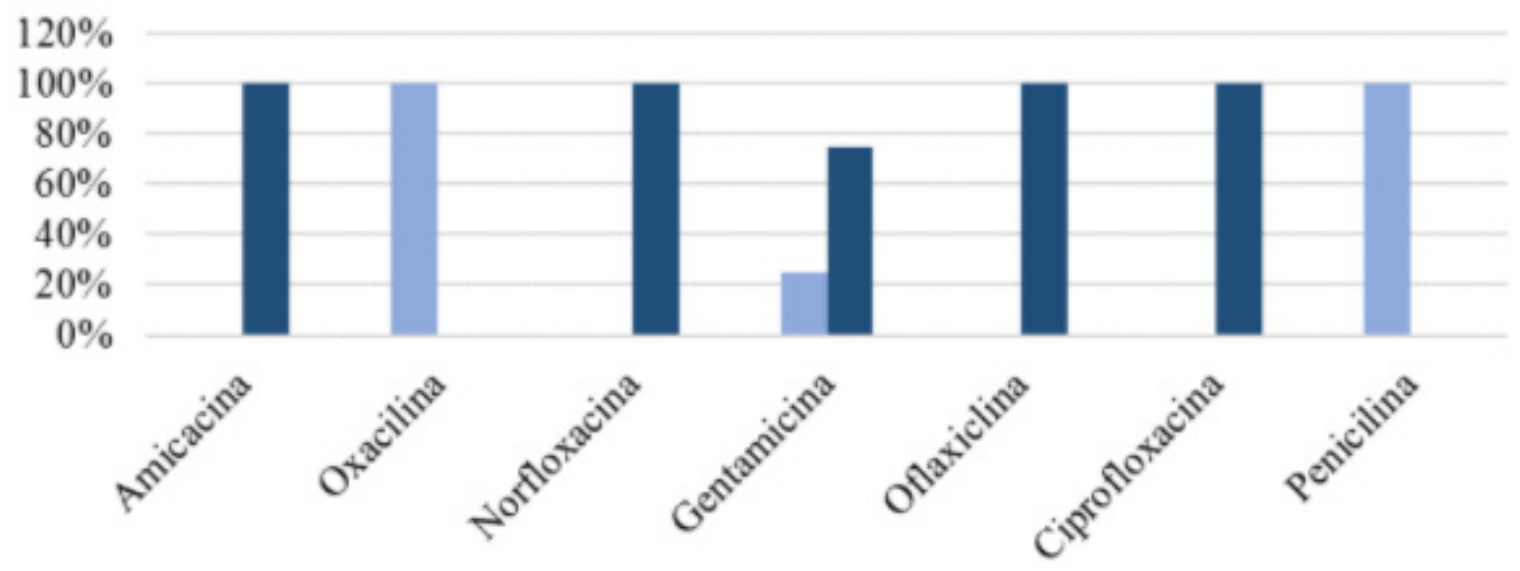

= Resistente " Sensível

No Gráfico 4 é exposto o perfil obtido no antibiograma de Streptococcus sp. encontrados nas amostras, sendo sensíveis, em 100\%, para os antibióticos Amicacina e Oflaxacina, 'já a maior resistência se deu para a Penicilina (80\%).

Gráfico 4: Perfil de resistência dos Streptococcus sp. encontradas nas amostras de fones de ouvido de uma instituição de ensino superior de Juazeiro do Norte-CE.

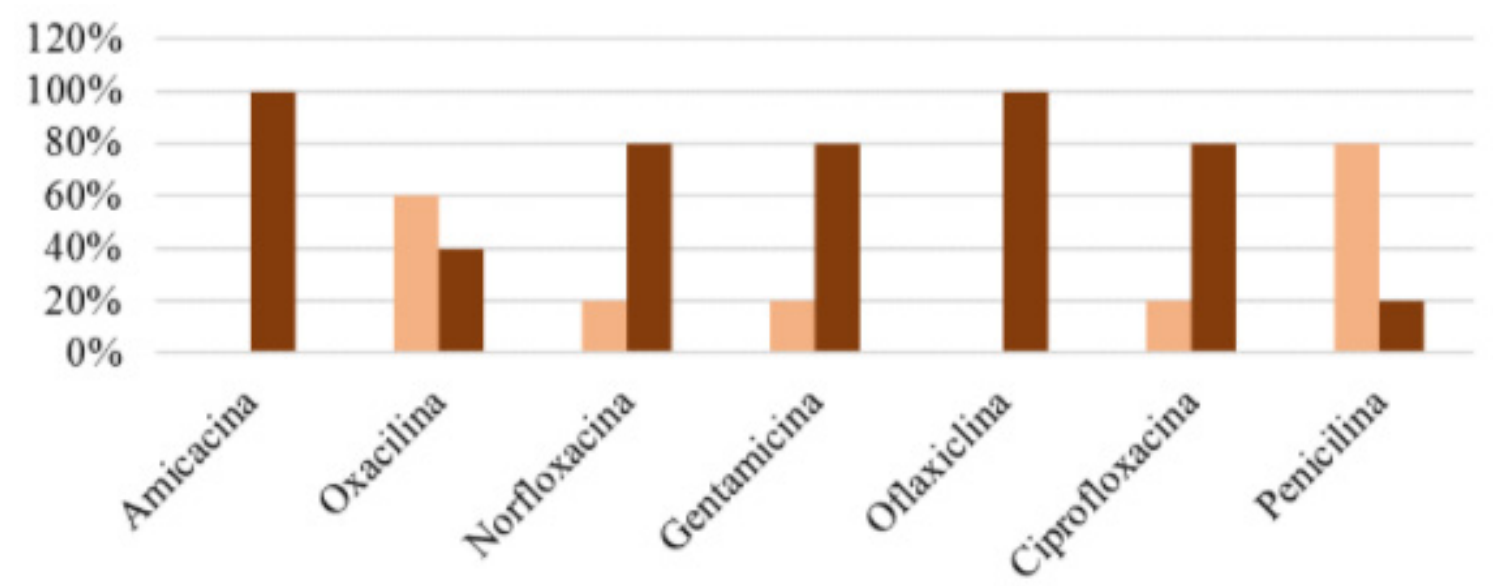

Resistente • Sensível

\section{DISCUSSÃO}

Em 100\% das amostras adquiridas aleatoriamente para o presente estudo houve crescimento de mais de um microrganismo por cada amostra. S. aureus com $70 \%$ e SCoN com 30\%, como também foi observado nas avaliações realizadas por Silva et al. $(2014)^{13}$ e Valente $(2017)^{3}$, nas quais foram encontradas maior prevalência de S. aureus.

Os SCoN são encontrados na microbiota normal da pele e podem ocasionar infecções relevantes como 
bacteremia e endocardite. Neste caso, um exemplo é a bactéria S. epidermidis, que é a espécie mais encontrada na pele dos seres humanos, tornando-se principal responsável pela sepse neonatal, além de estar relacionadas também com infecções de cateteres, próteses, marcapassos e pacientes imunocomprometidos ${ }^{14}$.

Essa predominância de Staphylococcus aureus está relacionada com a colonização da pele, uma vez que a bactéria faz parte da microbiota normal dos seres humanos. É um patógeno oportunista que contempla uma grande quantidade de infecções clínicas sejam elas superficiais ou invasivas, podendo assim apresentar os inúmeros fatores de virulência e estratégias para fugir do sistema imunológico ${ }^{15}$.

As bactérias que apresentaram uma menor porcentagem foram Enterobacter aeregenes com 2,5\% e Citrobacter freundii com 7,5\% de crescimento, ambas pertencentes à família Enterobacteriaceae. Teixeira e Silva $(2017)^{16}$ e Santana et al. (2019) ${ }^{17}$, verificaram aparelhos celulares, esses que, assim como fones de ouvido, entram em contato com o canal auditivo humano, o que ocasionalmente, podem apresentar um poder de disseminação no ambiente tornando-se um veículo de dispersão, assim como aparelhos de comunicação ${ }^{18}$.

O fungo filamentoso Candida sp. foi encontrada em 35\% das amostras analisadas, sendo encontrada também em um estudo realizado com fones de ouvidos realizado por Neto e colaboradores $(2012)^{18}$, assim como Garcia e colaboradores $(2018)^{5}$ esses fungos podem estar presentes na cavidade nasal e no coro cabeludo, ou seja, alguns fungos são parasitas dos seres humanos, porém podem desencadear infecções leves ou sistêmicas.

Estudos relacionados ao isolamento de Streptococcus sp em fones de ouvidos são escassos na literatura, sendo que no presente estudo foi observado crescimento de 12,5\% no Ágar sangue. Esses podem ser encontrados no trato gastrointestinal, geniturinário e na microbiota normal, é responsável por sepse neonatal ${ }^{19}$.

O antibiograma é um método empregado para medir a sensibilidade dos microrganismos frente aos antibióticos, através de disco-difusão, considerado um teste barato, fácil aplicação e interpretação ${ }^{20}$. É considerado um teste de extrema importância, uma vez que permite analisar e escolher o melhor antibiótico para o tratamento antibacteriano, consequentemente contribuindo para o controle de uma resistência antimicrobiana ${ }^{21}$.

Segundo Lima (2015) ${ }^{22}$ grande parte das cepas resistentes de Staphylococcus aureus é devido ao plasmídeo que codifica a $\beta$-lactamase, e relata ainda os mecanismos de resistência que são de uma aquisição de um gene com resistência ou de uma mutação que vai ocorrer em um gene do cromossomo.

Um estudo realizado por Ribeiro $(2014)^{23}$, as cepas de S. aureus foram resistentes em $100 \%$ à Oxacilina, já em outro estudo, Valente $(2017)^{3}$ avaliou a resistência dessa mesma bactéria em de fones de ouvido pertencentes a acadêmicos de medicina e neste caso foi observado 100\% de sensibilidade da bactéria no antibiótico de Oxacilina, entretanto, no presente estudo $78,6 \%$ dessas bactérias foram resistentes.

As cepas de Enterobacter sp. produzem beta-lactamase de amplo espectro, tornando difícil o tratamento 
com antibióticos. A ingestão de fármacos inapropriados pode cooperar para a transferência de plasmídeos e ilhas de patogenicidade ocasionando uma imediata resistência, principalmente aos membros da família Enterobacteriaceae ${ }^{24}$.

No estudo feito por Silva $(2015)^{25}$ onde foi identificado Streptococcus e feito o perfil de resistência, a Penicilina foi sensível em $97,6 \%$ entrando em discordância com o presente trabalho que foi apenas 20\%, e Ciprofloxacina com sensibilidade de $92,7 \%$ corroborando com o resultado obtido neste trabalho.

\section{CONSIDERAÇÕES FINAIS}

Diante dos resultados obtidos foi possível comprovar que os alunos de uma instituição de ensino superior que utilizam fones de ouvidos não fazem uma higienização correta. Tendo em vista que foi observado crescimento bacteriano em todas as amostras adquiridas, esses microrganismos podem estar presente devido a uma má higienização acompanhado de diversos ambientes que os fones são expostos.

Foi possível observar resistência em algumas cepas, em relação aos antibióticos Penicilina e Oxacilina sendo que dois de sete antibióticos apresentaram-se resistentes, demonstrando a relevância do antibiograma e comprovando que também é possível encontrar bactérias resistentes fora do ambiente hospitalar.

Baseado nos resultados obtidos é necessário que os discentes tenham um cuidado maior com os fones de ouvidos uma vez que, eles mal higienizados podem aglomerar diversos tipos de bactérias e podem causar infecções no canal auditivo, e com uma higienização correta podem minimizar os riscos.

\section{REFERÊNCIAS}

1. Moraes AL, Araúijo NGP, Braga TDL. Automedicação: revisando a literatura sobre a resistência bacteriana aos antibióticos. Rev Eletr Estácio Saúde. 2016;5(1):122-132.

2. Macedo GL, Falcão LFR. Farmacologia Aplicada em Medicina Intensiva. São Paulo: Editora Roca. 2011;1(1).

3. Valente MCM, de Araújo Soares FP, de Araújo Melo L, Silva JF, Porfírio Z, Barros YVR. Análise da contaminação e perfil de resistência aos antimicrobianos de Staphylococcus aureus isolados de fones de ouvido. In 69a Reunião Anual da SBPC, 2017, Minas Gerais. Anais/Resumos da 69ª Reunião Anual da SBPC. Minas Gerais: UFMG, 2017.

4. Speri MR, Araújo FC, Pontes MP, Silva JF. Recursos de biossegurança na avaliação audiológica básica: estudo comparativo entre o uso do protetor descartável de fone de ouvido e o uso do policloreto de vinila (PVC). Dist Comunic. 2017;29(2):292-301. 
5. Garcia CTP, Saleh DMFVB, Sasagawa SM, Mimica LMJ, Ueda SMY. Pesquisa de micro-organismos em canetas esferográficas utilizadas por estudantes universitários/Survey of micro-organisms in pens used by university students. Arquivos Médicos dos Hospitais e da Faculdade de Ciências Médicas da Santa Casa de São Paulo. 2018;57(1):6-10.

6. Barcelos DD, Dazzi NS. Efeitos do mp3 player na audição. Rev CEFAC. 2014;16(3):779-91.

7. Garbe CA, Jorge RMN, Costa MFG. Estudo biomecânico para reabilitação do ouvido médio humano. 2010. Dissertação (Mestrado em Engenharia Biomédica) - Faculdade de Engenharia da Universidade do Porto, Porto, 2010.

8. Oliveira MDFFD, Andrade KCLD, Carnaúba ATL, Peixoto GDO, Menezes PDL. Fones de ouvido supra-aurais e intra-aurais: um estudo das saídas de intensidade e da audição de seus usuários. Audiol Commun. Res. 2017;22(e1783-e1783).

9. Mattos GN, Lima LG, Vieira VF, Duarte SFP. Avaliação de Coliformes Totais e Escherichia coli em Diferentes Lotes de Água Mineral Comercializadas em um Município do Sudoeste Baiano. ID On Line Rev Multid Psicol. 2017;11(38):566-572.

10. Brasil. Agência Nacional De Vigilância Sanitária. Resolução da diretoria colegiada - RDC $n^{\circ} 26$, de 13 de maio de 2014. Disponível em: <http://bvsms.saude.gov.br/bvs/saudelegis/anvisa/2014/rdc0026_13_05_2014.pdf> Acessado em: 02 mar. 2018.

11. Arantes T, Paixão GOD, Silva MD, Castro CSA. Avaliação da colonização e perfil de resistência de Staphylococcus aureus em amostras de secreção nasal de profissionais de enfermagem. Rev Bras Farm. 2013;94(1):30-34.

12. CLSI, Performace Standards for Antimicrobial Susceptibility Testing; Twenty-Third Informational Supplement. CLSI Document M100-s23. Clinical and Laboratory Standards Institute, Wayne, PA, (2013). Available from: https://www. facm.ucl.ac.be/intranet/CLSI/CLSI-M100S23-susceptibility-testing-2013-no-protection.pdf.

13. Silva MHR, Barreto Gotardi AH, de Barros AAS, Barcelos Blini RC, Bernardes LG, Machado ARSR, et al. Isolamento e identificação de microrganismos presentes em superfícies de teclados e mouses de uma universidade de Três Lagoas, MS. Colloquium Vitae. 2014;6(3).

14. Araújo MQ, Poletto KQ, Bessa NG. Perfil de resistência bacteriana em fômites de uti em hospital público do estado do Tocantins. Rev Cereus. 2017;9(2):126-141.

15. Evangelista SDS, Oliveira ACD. Staphylococcus aureus meticilino resistente adquirido na comunidade: um problema mundial. Rev Bras Enferm. 2015;68(1):136-143.

16. Teixeira F, Silva, CD. Análise microbiológica em telefones celulares. Rev F@ pciência. 2017;11(3):15-24.

17. Santana VTP, Duarte PM, Fernandes UA, Damião GM, Silva AL. Análise Microbiológica em Aparelhos de Celular de Acadêmicos e Professores da Universidade de Cuiabá (UNIC) Campus Primavera do Leste-MT. UNICIÊNCIAS. 
2019;23(2):105-109.

18. Neto AC, Hardoim EL, Macanham DC, Silva APC. Flora microbiana de telefones públicos localizados no campus de uma universidade pública em Cuiabá. Rev Eletr Biol. 2012;5(2):56-72.

19. Kiss FS, Rossato JDS, Graudenz MS, Gutierrez LLP. Prevalência da colonização por Streptococcus agalactiae em uma amostra de mulheres grávidas e não grávidas de Porto Alegre, estado do Rio Grande do Sul. Scientia Medica. 2013;23(3).

20. Magalhães TV, Lot RFE, Del Carratore CR. Análise da ação antibacteriana da própolis e padronização de volumes através de antibiograma. Rev Unimar Ciênc. 2017;25(1-2).

21. Pereira SCL, Ribeiro RS, Bazzolli DMS, Vanetti MCD. Resistência a antibióticos e presença de plasmídeos em enterobactérias e Staphylococcus aureus isoladas do setor de dietética de um hospital público. O Mundo da Saúde. 2015;39(2):147-156.

22. Lima MFP, Borges MA, Parente RS, Júnior RCV, de Oliveira ME. Staphylococcus aureus e as infecções hospitalares-Revisão de Literatura. Rev Uningá Review. 2015;21(1).

23. Ribeiro IF, Silva SFR, Ribeiro TR, Rocha MMNP, Stolp MV. Identificação de Staphylococcus aureus e Staphylococcus aureus resistente à meticilina em estudantes universitários. Rev Ciênc Farmac Básica e Aplic. 2015;35(2):301304.

24. Cergole-Novella MC, Pignatari ACC, Castanheira M, Guth BEC. Molecular typing of antimicrobial-resistant Shiga-toxin-producing Escherichia coli strains (STEC) in Brazil. Res in Microbiol. 2011;162(2):117-123.

25. Silva VL. Análise da frequência e do perfil de sensibilidade de cepas de Streptococcus Agalactiae isolados em urocultura na Regional de Ceilândia. Trabalho de Conclusão de Curso (Bacharelado em Farmácia) - Universidade de Brasília, Faculdade de Ceilândia. 2015. 